\title{
The evaluation of ultrasonography results of patients with a fine needle aspiration biopsy and pathology diagnosis of papillary thyroid cancer: a single center study
}

\begin{abstract}
Aim: We aimed to measure the accuracy of the results of FNAB (fine needle aspiration biopsy) and preoperative ultrasonography (US) in patients whose pathologic diagnosis was thyroid cancer and who underwent total thyroidectomy in this study.

Material and method: A total of 43 patients who had undergone thyroidectomy between January 2012 and September 2017 were included in the study. The data of the patients who underwent FNAB following US investigation at our clinic and were diagnosed with thyroid cancer after surgery were evaluated retrospectively. Multinodular tissue formation was present on thyroid ultrasonography in all patients. The findings that were accepted as ultrasonographically suspicious for malignancy during nodule evaluation were as follows:
i. a solid and hypoechogenic nodule,
ii. a nodule with microcalcifications,
iii. a nodule with irregular borders,
iv. a nodule without a halo,
v. the length of the nodule being longer than the width,
vi. increased nodule vascularity on Doppler ultrasonographic evaluation.

The number of nodules that underwent FNAB, the diameter, echogenicity (hyperechogenic, isoechogenic, hypoechogenic, heterogeneous), content (solid, solidcystic, cystic, microcalcification presence), the presence or absence of a peripheral halo, whether the border was regular or irregular, and whether the nodule was vascular were noted in the US reports. Fine needle aspiration biopsy results and postoperative pathologic diagnoses and ultrasonographic findings of the patients diagnosed with papillary thyroid carcinoma were compared.

Results: Of the patients who underwent thyroidectomy, 36(83.72\%) were female and $7(16.28 \%)$ were male. The mean age was $48.14 \pm 12.75$ years. A family history of thyroid or other cancers was present in 9 patients. The pathology results of the 43 patients whose previous fine needle aspiration biopsy result was papillary thyroid cancer were also consistent with papillary thyroid cancer. Of the patients found to have thyroid cancer, papillary carcinoma was present in 28 patients and papillary microcarcinoma in 15 patients. Although the incidence of malignancy was high in solid hypoechogenic nodules, nodules with vascularization, nodules with an anterior-posterior diameter/ transverse diameter ratio $>1$ and nodules without a halo in our study, the incidence of malignancy was seen to be less in patients who had a nodule with microcalcification and an irregular border. The incidence of cancer was high in nodules $1-4 \mathrm{~cm}$ in size.

Conclusion: FNAB should be performed in patients with a nodule and suspicious US findings to decide whether they should undergo surgery. US is a guiding and noninvasive examination that can reduce the unnecessary FNAB and surgery rate in US patients.

Keywords: preoperative ultrasonography, diagnosis, thyroid nodules, cancer, solid structure, calcification, hypoechogenicity, irregular borders
Volume 4 Issue 4 - 2017

Tülay Diken Allahverdi,' Ahmet Erdem²

'Department of General Surgery, University of Kafkas, Turkey

${ }^{2}$ Department of Radiology, University of Kafkas, Turkey

Correspondence: Tülay Diken Allahverdi, Department of General Surgery, University of Kafkas, Turkey, Tel 0506631965I, Email drtulaydiken@hotmail.com

Received: October 28, 2017 | Published: November 15, 2017
Abbreviations: FNAB, fine needle aspiration biopsy; US, ultrasonography

\section{Introduction}

Thyroid nodules are common in the community, but thyroid cancers constitute less than $1 \%$ of all cancers. ${ }^{1}$ Although this rate is low, early diagnosis is crucial because thyroid cancers are usually slowly progressive and the life expectancy of patients after treatment is long. Performing radiologic imaging in patients whose examination reveals thyroid nodules is important as regards early diagnosis and 
determining the follow-up and treatment options. The purpose of the diagnosis of thyroid nodules is to ensure that malignant nodules that are seen rarely are diagnosed accurately and surgically removed and that patients diagnosed with benign nodules are protected from unnecessary surgical procedures. ${ }^{2}$ Fine needle aspiration biopsy (FNAB) is the first choice in the differentiation of benign and malignant thyroid lesions and the diagnosis. The diagnosis rate can be increased when FNAB is accompanied by ultrasonography, especially in deeply located small nodules, and the diagnosis of thyroid cancers at an earlier stage can be ensured. US findings such as solid structure, calcification, hypoechogenicity, irregular borders, and lack of a peripheral halo have been identified as factors differentiating benign and malignant thyroid nodules. ${ }^{3}$ Such differentiation should be made by performing fine needle aspiration biopsy for thyroid nodules larger than $10 \mathrm{~mm}$ without prominent risk factors while nodules smaller than $10 \mathrm{~mm}$ should be evaluated with fine needle aspiration biopsy if they show suspicious ultrasonographic features. ${ }^{4}$ Although the cancer risk is known to increase with the size of the thyroid nodule, size is not a criterion for surgery by itself. Thyroid ultrasonography is an important test in determining the treatment method. ${ }^{4-6}$ Although fine needle aspiration biopsy (FNAB) is accepted to be highly sensitive, ultrasonography (US) findings should not be overlooked in the evaluation of thyroid nodules. We aimed to measure how accurate FNAB results and preoperative ultrasonographic findings were in patients who underwent total thyroidectomy with a pathology diagnosis of thyroid cancer in this study.

\section{Material and methods}

A total of 43 patients who had undergone thyroidectomy between January 2012 and September 2017 were included in the study. The data of the patients who had undergone FNAB following US at our clinic and were diagnosed with thyroid cancer after surgery were retrospectively evaluated. Multinodular tissue formation was present on thyroid ultrasonography in all patients. The findings accepted as ultrasonographically suspicious in terms of nodule malignancy were as follows: 1) a solid and hypoechogenic nodule, 2) a nodule containing microcalcifications, 3) a nodule with irregular borders, 4) a nodule without a halo, 5) larger nodule length than width and 6) increased nodule vascularity on Doppler ultrasound evaluation (Table 1). The number of nodules, the diameter, echogenicity (hyperechogenic, isoechogenic, hypoechogenic, heterogeneous), content (solid, solidcystic, cystic, microcalcification presence), the presence or absence of a peripheral halo, whether the nodule borders were regular or irregular, and whether the nodule was vascular were noted in the USG reports. Fine needle aspiration biopsy results and postoperative pathology diagnoses and ultrasonographic findings were compared in patients diagnosed with papillary thyroid carcinoma.

Table I The findings accepted as ultrasonographically suspicious in terms of nodule malignancy

\begin{tabular}{ll}
\hline I & Solid and hypoechogenic nodule \\
2 & A nodule containing microcalcifications \\
3 & A nodule with irregular borders \\
4 & A nodule without a halo \\
5 & Larger nodule length than width \\
6 & İncreased nodule vascularity
\end{tabular}

\section{Statistical analysis}

Mean and percentage calculations were performed by entering the data in a database prepared in the Statistical Package for the Social
Sciences (SPSS) software, version 17.5.

\section{Results}

The patients who underwent total thyroidectomy consisted of $36(83.72 \%)$ females and $7(16.28 \%)$ males. The mean age was $48.14 \pm 12.75$ years. A family history of thyroid or other cancers was present in 9 patients. The pathology results of the 43 patients with a previous needle aspiration biopsy result of papillary thyroid cancer were also consistent with papillary thyroid cancer. Among the patients found to have thyroid cancer, papillary carcinoma was present in 28 patients and papillary microcarcinoma in 15 patients. FNAB was found to have been performed on the dominant nodule in 9 patients with papillary microcarcinoma. Both dominant and non-dominant malignant nodules showed at least 2 suspicious US findings (Table 1). The tumor was multicentric in 10 of the patients with thyroid cancer. Capsule invasion was present in 15 patients. As mentioned previously, the cancer was seen to emerge in nodules with suspicious US findings, except the 15 patients with papillary microcarcinoma. The US properties of the nodules are presented in Table 2. No cystic lesion was seen on US. Solid features were detected in the malignant nodules in 20 patients $(46.50 \%)$ and semisolid features in 23 patients (53.48\%). Nodule hyperechogenicity was not detected in any patient diagnosed with malignancy while isoechogenicity was found in $12(27.90 \%)$ patients and hypoechogenecity in $31(72.09 \%)$ patients. Malignant nodule borders were well-defined in $21(48.83 \%)$ patients, microlobulated in $14(18.60 \%)$ and irregular in $8(18.60 \%)$ patients. Microcalcification was found in 9 patients $(20.93 \%)$, macrocalcification in 2 patients $(4.65 \%)$, and no calcification in 32 patients $(74.41 \%)$ with malignant nodules. Peripheral vascularization was found in $13(30.23 \%)$, central vascularization in $8(18.60 \%)$, peripheral and central vascularization together in $15(34.88 \%)$ patients, and no vascularization in $7(16.27 \%)$ patients. A hypoechogenic halo appearance was present in 3(6.97\%) patients and absent in 40(93.02\%) patients with malignant nodules. Less than $1 \mathrm{~cm}$ was found in 7 patients (16.27\%), $1-4 \mathrm{~cm}$ size in 32 patients $(74.41 \%)$, and over $4 \mathrm{~cm}$ in 4 patients $(9.30 \%)$

Table 2 Ultrasonographic findings of the patients diagnosed with papillary thyroid carcinoma.

\begin{tabular}{llll} 
Content & Echogenicity & Borders & Size \\
\hline Solid: 20, & Hyperechogenic & Regular: & \\
$\% 46.50$, & $: 0$, İsoechogenic: & $21, \% 48.83$, & Less than Icm: \\
Semisolid: & I2, \%27.90, & microlobulate: 14, & $7 . \% 16,27 \mathrm{I}-4 \mathrm{~cm}:$ \\
$23, \% 53.48$ & Hypoechogenic: & $\% 18.60$, İrregular: & 32.41 Over \\
Cystic: 0 & $31, \% 72.09$ & $8, \% 18.60$ & $4.69,30$
\end{tabular}

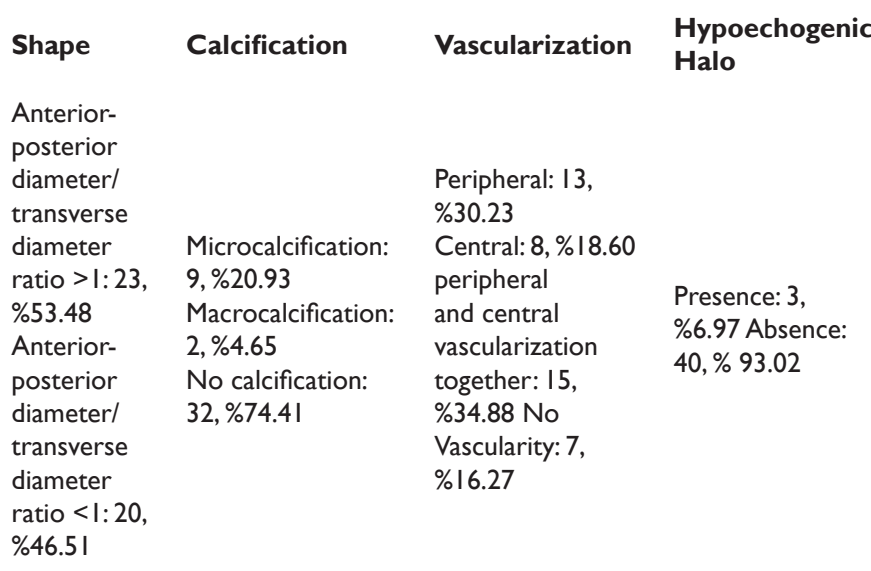




\section{Discussion}

Even nodules that cannot be palpated can now be demonstrated in thyroid and neck ultrasonographic investigations with the new highresolution ultrasonography devices. ${ }^{7,8}$ Although thyroid carcinomas grow slowly and therefore have low morbidity and mortality, they can also lead to extracapsular growth and lymph node and distant organ metastasis.. ${ }^{9}$ Fine needle aspiration biopsy is the primary and most common method for the histological characterization of thyroid nodules. Diagnosis of thyroid cancer with this method has increased almost $100 \%$ and patients can now be protected from unnecessary surgical interventions. ${ }^{10}$ Although fine needle aspiration biopsy is easier than surgery, is it logical to perform fine needle aspiration biopsy for every nodule? This is a controversial issue as some patients may not want to undergo fine needle aspiration biopsy due to the related anxiety and pain. In this case, ultrasonography findings can help us determine which nodule should be used for the fine needle aspiration biopsy. Patients can be screened for cancer by performing fine needle aspiration biopsy only for nodules with suspicious ultrasound findings. Such suspicious ultrasonographic findings include a solid component, hypoechogenicity, microlobulation or irregular borders, microcalcifications, and shape characteristics ("taller-than-wide shape"). ${ }^{11}$ Papini et al. ${ }^{9}$ found an increased possibility of malignancy in hypoechogenic nodules with irregular borders and those containing microcalcification in their study on FNAB accompanied with US fornon-palpable thyroid nodules. ${ }^{9}$ Bayrak et al. ${ }^{12}$ reported malignant nodules to be associated with a solid internal structure, hypoechogenicity, microcalcification and irregular borders. ${ }^{12}$ The Moon et al. study with a large series found that malignant nodules had a heterogeneous internal structure but this result was not statistically significant. ${ }^{13}$ Yüksekkaya et al. ${ }^{3}$ reported that hypoechogenicity and irregular borders were important criteria for the differentiation of benign and malignant nodules but the number of nodules and their dimensions, the calcification of the nodules, cystic area, whether a halo was present, the shape characteristics and other characteristics such as echo structure did not have statistical significance in differentiating benign and malignant nodules. Benign characteristics were reported in most of the mixed nodules after surgery in their study. ${ }^{3}$ We found ultrasonography to reveal a high rate of malignancy in hypoechogenic nodules, nodules with a solid structure, and those without a halo in our study. However, in contrast to the literature, we found higher rates of malignancy in nodules with a regular border. Again in contrast to the literature, malignancy was more common in the nodules where calcification was absent but macrocalcification was present. Color Doppler US is used in the differential diagnosis of thyroid gland pathologies together with US as it can show intraparenchymal blood flow, enable evaluation of vascularity in thyroid tumors and tumor-like lesions, and directly measure thyroid blood flow. ${ }^{14}$ Increased vascularization inside the nodule and a disorganized vascular structure should be considered as evidence for malignancy. However, a hypovascular or avascular state does not rule out the possibility of malignancy in that nodule. It should also be kept in mind that increased vascularity in the center of large benign nodules could also be detected with high-resolution devices. ${ }^{15}$ We observed peripheral and central vascularization in association and the malignancy rate was higher in the nodules with peripheral and central vascularization. A posterior diameter/ transverse diameter ratio above 1 has been reported to indicate a high possibility of nodule malignancy. ${ }^{15}$ We also found higher rates of malignancy in nodules with an anterior-posterior diameter/transverse diameter ratio $>1$ in our study. Çahalov et al. ${ }^{5}$ reported that the risks of extracapsular invasion and lymph node metastasis were higher in papillary type carcinoma than follicular type carcinoma and also as the nodule diameter increased in papillary and micropapillary thyroid cancers. The risk of distant metastasis increased as the size of the primary tumor reached $2 \mathrm{~cm}$ and early diagnosis decreased the risk of relapse and mortality in thyroid cancer. It was emphasized in the same study that the ultrasonographic features of the nodules can be used to differentiate malignant and benign thyroid nodules $1-2 \mathrm{~cm}$ in diameter and that the number of unnecessary FNAB procedures can be decreased by such differentiation of nodules requiring biopsy. ${ }^{5}$ Kim et al. ${ }^{4}$ stated that FNAB should be performed for nodules smaller than $1 \mathrm{~cm}$ with suspicious US findings as the malignancy rate was high in such nodules. FNAB and post-surgical pathology diagnoses of patients with at least two suspicious US findings in nodules with a size of less than $1 \mathrm{~cm}, 1-4 \mathrm{~cm}$ and over $4 \mathrm{~cm}$ were consistent with papillary thyroid cancer in our study.

\section{Conclusion}

FNAB should be performed on nodules with at least two suspicious US findings so that a decision can be made regarding surgery. US is a guiding and non-invasive method that can reduce the rate of unnecessary FNAB and surgery.

\section{Acknowledgements}

None.

\section{Conflict of interest}

Author declares that there is no conflict of interest.

\section{References}

1. https://nobeltip.com/

2. Degirmenci B, Haktanir A, Albayrak R, et al. Sonographically guided fine-needle biopsy of thyroid nodules: the effects of nodule characteristics, sampling technique, and needle size on the adequacy of cytological material. Clin Radiol. 2007;62(8):798-803.

3. Yüksekkaya ZR, Çelikyay F. Benign ve malign tiroid nodüllerinde ultrasonografi bulguları. Firat Üniversitesi Să̆Bil Tıp Der. 2011;25:77-82.

4. Kim GR, Kim MH, Moon HJ, et al. Sonographic characteristics suggesting papillary thyroid carcinoma according to nodule size. Ann Surg Oncol. 2012;20(3):906-913.

5. Çahalov M, Makay Ö, İçöz G, et al. What should be done in thyroid nodules less than two centimeters, ultrasonographically suspicious and cytologically benign? Ulusal Cer Derg. 2013;29:167-170.

6. Sakorafas GH, Mastoraki A, Lappas C, et al. Small $(<10 \mathrm{~mm})$ thyroid nodules; how aggressively should they be managed? Onkologie. 2010;30(1-2):61-64.

7. Ezzat S, Sarti DA, Cain DR, et al. Thyroid incidentalomas: prevalence by palpation and ultrasonography. Arch Intern Med. 1994;154(16):1338-1340.

8. Watters DAK, Ahuja AT, Evans RM, et al. Role of ultrasound in the management of thyroid nodules. Am J Surg. 1992;164(6):654-657.

9. Papini E, Guglielmi R, Bianchini A, et al. Risk of malignancy in nonpalpable thyroid nodules: predictive value of ultrasound and color Doppler features. J Clin Endocrinol Metab. 2002;87(5):1941-1946. 
10. Bonavita JA, Mayo J, Babb J, et al. Pattern Recognition of Benign Nodules at Ultrasound of the Thyroid: Which Nodules Can be Left Alone? AJR Am J Roentgenol. 2009;193(1):207-213.

11. Kwak JY, Han KH, Yoon JH, et al. Thyroid imaging reporting and data system for US features of nodules: a step in establishing better stratification of cancer risk. Radiology. 2011;260(3):892-899.

12. Bayrak AH, Özel A, Peker K. Tiroid Nodüllerinde Endikasyonlara Göre İnce İğne Aspirasyon Biyopsisi Sonuçları. Dicle Tıp Dergisi. 2007;34(1):42-47.
13. Moon WJ, Jung SLJ, Lee JH, et al. Benign and malignant thyroid nodules: US differentiation-multicenter retrospective study. Radiology. 2008;247(3):762-770

14. Castagnone D, Rivolta R, Rescalli S, et al. Color Doppler sonography in Graves' disease: value in assessing activity of disease and predicting outcome. AJR Am J Roentgenol. 1996;166(1):203-207.

15. Önver H, Özbey AO, Duymuș M, et al. Evaluation of Ultrasonographic, Cytological and Histopathological Findings of Thyroid Nodules. Kafkas J Med Sci. 2013;3(2):80-87. 